\title{
Effect of prescribed temperature on mixed convection boundary layer in the unsteady stagnation point flow toward a stretching vertical sheet
}

\begin{abstract}
The solution to the unsteady mixed convection boundary layer flow and heat transfer problem due to a stretching vertical surface is presented in this paper. The unsteadiness in the flow and temperature fields is caused by the time-dependent of the stretching velocity and the surface temperature. The effects of the unsteadiness parameter, buoyancy parameter and Prandtl number on the flow and heat transfer characteristics are thoroughly examined. It is observed that the solutions exist for all values of buoyancy parameter. Comparison with known results for steady-state flow is excellent.
\end{abstract}

Keyword: Stretching sheet; Unsteady stagnation flow 